\title{
ANALISIS TOTAL PRODUCTIVE MAINTENANCE (TPM) PADA STASIUN KERNEL CRUSHING PLANT (KCP) DI PT.X
}

\author{
Nina Hairiyah, Raden Rizki Amalia, dan Rino Adi Wijaya \\ Jurusan Teknologi Industri Pertanian, Politeknik Negeri Tanah Laut \\ Email: $\mathrm{C}$
}

\begin{abstract}
ABSTRAK
PT. X merupakan industri pengolahan kelapa sawit yang menghasilkan produk CPO dan PKO. Pada proses produksi di PT. X, mesin yang sering mengalami downtime besar dan breakdown paling banyak terjadi pada mesin First Press di stasiun Kernel Crushing Plant (KCP). Berdasarkan hal tersebut, maka penelitian ini bertujuan untuk melakukan analisis Total Productive Maintenance (TPM) dengan menggunakan Overall Equipment Effectiveness (OEE) pada mesin first press di stasiun KCP. Data yang digunakan berupa data teoritis dan historis mengenai TPM, OEE, dan jam kerja mesin first press. Hasil analisis menunjukkan bahwa nilai OEE pada mesin first press di stasiun KCP PT. X belum memenuhi standar internasional yang telah ditetapkan. Nilai OEE untuk mesin first press pada stasiun KCP memiliki nilai sebesar $68,26 \%$ dengan selisih yang cukup jauh dengan nilai standar Internasional yaitu sebesar $85 \%$. Penyebab rendahnya nilai OEE mesin first press di stasiun KCP PT. X karena faktor umur mesin yang sudah tua, proses maintenance yang lama, serta kualitas kernel yang rendah.

Kata kunci-mesin first press; Overall Equipment Effectiveness (OEE); stasiun Kernel Crushing Plant (KCP), Total Productive Maintenance (TPM)
\end{abstract}

\section{PENDAHULUAN}

Kelancaran suatu sistem atau suatu proses produksi memerlukan dukungan dari beberapa aspek, diantaranya adalah maintenance (perawatan) mesin dan availability (ketersediaan) mesin yang terdapat pada sistem produksi tersebut. Perawatan meliputi usaha-usaha yang dilakukan untuk menjamin mesin bekerja dengan baik, efektif, efisien, ekonomis, fungsional dan optimal. Maka dari itu diperlukan suatu manajemen perawatan yang baik dalam rangka menunjang kegiatan maintenance. Untuk membuat kegiatan manajemen perawatan menjadi lebih baik, maka dibutuhkan analisa yang dapat mengidentifikasi keefektifan kinerja suatu mesin, yang nantinya dapat digunakan sebagai dasar perlakuan terhadap gejala-gejala dari kerusakan, serta mampu mengantisipasi gejala-gejala tersebut dan menjamin kualitas produk, serta kemampuan ketersediaan mesin tersebut (Asgara dan Hartono, 2014).

PT. X merupakan industri yang menghasilkan produk Crude Palm Oil (CPO) dan Palm Kernel Oil (PKO) dari pengolahan kelapa sawit. Pengolahan CPO terdiri dari stasiun Penerimaan Buah, Sterilizer, Tippler, Thressing, Press, dan Klarifikasi. Adapun untuk stasiun pengolahan PKO yaitu stasiun Nut dan Kernel, dan stasiun Kernel Crushing Plant (KCP). Pada proses produksi di PT. X, mesin yang sering mengalami downtime besar dan breakdown paling banyak terjadi pada mesin First Press di stasiun Kernel Crushing Plant (KCP).

Salah satu cara untuk mengurangi dan mengatasi permasalahan tersebut, perusahaan memerlukan suatu kegiatan perawatan terhadap mesin maupun peralatan untuk memaksimalkan sumber daya yang ada, karena mesin merupakan komponen vital untuk melakukan proses produksi. Dalam mempertahankan mutu dan meningkatkan produktivitas, salah satu faktor penting yang harus diperhatikan adalah masalah perawatan mesin. Sebelum melakukan perencanaan perawatan perlu adanya analisa kinerja mesin yang sesuai agar dapat mengetahui faktor-faktor penyebab yang dapat mengurangi kinerja mesin dengan menggunakan konsep TPM.

Total Productive Maintenance (TPM) adalah total dari pemeliharaan produktif secara permanen untuk meningkatkan keseluruhan efektifitas peralatan dengan melibatkan operator secara aktif (Hartmant, 1992). Adanya TPM dimaksudkan agar kombinasi antara produksi danpemeliharaan secara bersama-sama mengalami peningkatan berkelanjutan (Pomorski, 2004). Pemeliharaan yang baik sangat penting untuksistem produksi yang produktif. TPM juga merupakan pendekatan alternatif 
untukpemeliharaan peralatan yang berupaya mencapai nolkerusakan dan nol cacat. Selain itu TPM juga merupakan pendekatan untuk menjagapabrik dan peralatan saat ini agar lebih tinggi tingkat produktifnyamelalui kerja sama semua bidang organisasi dalam perusahaan (Rajput dan Jayaswal, 2012).

Beberapa penelitian yang bertujuanmengukur kinerja mesin dan mencari faktor-faktor penyebab yang dapat mengurangi kinerja mesin diantaranya adalah penelitian yang dilakukan oleh Muhsin (2016) dan penelitian Rahmad, Pratikto, dan Wahyudi (2012) dengan menggunakan Overall Equipment Effectiveness (OEE) dalam implementasi Total Productive Maintenance (TPM). Hasil penelitian menunjukkan nilai OEE yang didapatkan masih berada di bawah standar, sehingga dilanjutkan dengan analisis mencari faktor penyebab permasalahan menggunakan metode diagram ishikawa.

Selain itu Rinawati dan Dewi (2014), juga telah melakukan penelitian analisis TPM menggunakan OEE dan six big losses pada mesin cevitec di PT. Essentra Surabaya. Hasil penelitian menunjukkan bahwa rata-rata nilai OEE tergolong sangat rendah. Analisis untuk mengetahui faktor penyebab rendahnya nilai OEE dilanjutkan dengan menggunakan six big losses dan diagram ishikawa. Selanjutnya dalam penelitian yang dilakukan oleh Vittaleshwar, Shetty, \& Prajual (2016) didapatkan hasil bahwa TPM menggunakan OEE mampu membantu perusahaan pembuatan botol air untuk mengidentifikasi kerugian pada proses dan inefisiensi yang sebelumnya belum terdeteksi.

Pada tahun 2017, Supriyadi, Ramayanti, dan Afriansyah telah melakukan penelitian analisis TPM dengan metode OEE yang bertujuan untuk untuk mengetahui nilai OEE, mengetahui dampak gangguan belt sobek, mengetahui penyebab terjadinya belt conveyor sobek, dan melakukan estimasi hasil perbaikan dari sisi biaya. Hasil penelitian menunjukkan bahwa nilai OEE masih berada di bawah standar internasional, sehingga dilakukan langkah tindakan perbaikan menggunakan metode Fuzzy Failure Mode and Effect Analysis.

Berdasarkan beberapa permasalahan hasil studi pendahuluan di PT. X, serta membandingkan dengan beberapa penelitian yang relevan dengan menggunakan beberapa metode, maka tujuan dari penelitian ini adalah menganalisis keefektifan mesin first press pada Stasiun Kernel Crushing Plant (KCP) dengan menggunakan metode Overall Equipment Effectiveness (OEE) sebagai alat untuk mengukur kinerja dari sistem produktif pada mesin. Penggunaan metode ini diharapkan dapat mengetahui suatu penyebab sering terjadinya kerusakan pada mesin dari sumber atau faktor-faktor penyebab yang dapat merugikan perusahaan.

\section{METODOLOGI PENELITIAN}

\section{Waktu dan Lokasi Penelitian}

Penelitian ini dilaksanakan selama lima bulan yaitu pada bulan Agustus sampai dengan Januari 2018 yang berlokasi di salah satu perusahaan pengolah minyak sawit CPO dan PKO yaitu PT. X.

\section{Prosedur Penelitian}

Penelitian ini dilakukan dengan objek mesin first press pada stasiun Kernel Crushing Plant $(\mathrm{KCP})$ di PT. X. Data teoritis yang digunakan berupa teori mengenai total productive maintenance (TPM) dan overall equipment effectiveness (OEE). Data historis yang digunakan adalah data mengenai jam kerja untuk mesin first press. Setelah mendapatkan data, dilanjutkan dengan analisis perhitungan untuk mengetahui nilai OEE.

\section{Analisis Data}

1. Overall Equipment Effectiveness (OEE)

OEE memberikan gambaran mengenai kinerja mesin dan jumlah yang akurat untuk mengetahui tingkat keefektifan mesin yang digunakan (Wahid \& Agung, 2016). Tujuan OEE adalah sebagai alat ukur performa dari sistem maintenance, dengan menggunakan metode ini maka dapat diketahui ketersediaan mesin/peralatan, efisiensi produksi, dankualitas output mesin/peralatan. Untuk itu hubungan antara ketiga elemen produktifitas tersebut dapat dilihat pada rumus dibawah ini (Borris, 2006):

$O E E \%=A \times P \times Q \times 100 \%$ 
Keterangan: $\quad \mathrm{A}=$ Avalability (waktu ketersediaan mesin/peralatan)

$\mathrm{P}=$ Performance effectiveness

$\mathrm{Q}=$ Quality

\section{Availability}

Nakajima (1988) menyatakan bahwa availability merupakan rasio dari operationtime, dengan mengeliminasi downtime peralatan, terhadap loading time.

Availiability $=\frac{\text { operation time }}{\text { loading time }}=\frac{\text { loading time-down time }}{\text { loading time }}$

Adapun rumus yang digunakan untuk perhitungan loading time dan operating time adalah sebagai berikut:

Loading time $=$ Running time - Planned downtime

Operating time $=$ Loading time - Downtime

\section{Performance}

Performance ratio adalah rasio yang menggambarkan kemampuan peralatan dalam menghasilkan produk yang merupakan hasil dari operating speed rate dan netoperating rate. Operating speed rate berdasarkan perbedaan antara kecepatan ideal dan kecepatan operasi aktual. Net operating rate melakukan pengukuran suatu kecepatan dalam periode tertentu (Suhendra \& Betrianis, 2005).

Performance $=\frac{\text { processed amount } x \text { theoritical cycle time }}{\text { operation time }}$

\section{Quality}

Qualityratio adalah rasio yang menggambarkan kemampuan mesin dalam menghasilkan produk sesuai dengan spesifikasi yang telah ditetapkan.

Quality $=\frac{\text { processed amount }- \text { defect amount }}{\text { processed amount }}$

\section{HASIL DAN PEMBAHASAN}

\section{Availability}

Availability merupakan suatu rasio yang menggambarkan pemanfaatan waktu yang tersedia untuk kegiatan operasi mesin. Perhitungan availability yang pertama adalah menghitung loading time.Loading time adalah waktu bersih proses produksi dilaksanakan dalam jam kerja. Hasil dari perhitungan loading time bulan Agustus hingga Desember 2018 disajikan pada Tabel 1.

Tabel 1. Perhitungan Loading Time

\begin{tabular}{llcccc}
\hline No & Bulan & Jumlah Hari & $\begin{array}{c}\text { Jam Kerja } \\
\text { (menit) }\end{array}$ & $\begin{array}{c}\text { Planned Downtime } \\
\text { (menit) }\end{array}$ & $\begin{array}{c}\text { Loading Time } \\
\text { (menit) }\end{array}$ \\
\hline 1 & Agustus & 31 & 44.640 & 1200 & 43.440 \\
2 & September & 30 & 34.200 & 1200 & 33.000 \\
3 & Oktober & 31 & 44.640 & 1500 & 43.140 \\
4 & November & 30 & 34.200 & 1200 & 33.000 \\
5 & Desember & 31 & 44.640 & 1500 & 43.140 \\
\hline
\end{tabular}

Pada Tabel 1 dapat diketahui bahwa jam kerja pada stasiun KCP yaitu selama 24 jam setiap harinya yang dirubah satuannya menjadi menit untuk mempermudah dalam perhitungan. Data pada Tabel 1 menunjukkan total jam kerja yang berbeda-beda setiap bulannya karena memiliki jumlah hari yang berbeda setiap bulannya. 
Planned downtime adalah waktu yang dijadwalkan untuk melakukan perawatan atau monitoring selama jam kerja. Pada stasiun KCP telah dijadwalkan untuk melakukan perawatan yang diterapkan dalam satu minggu sekali yaitu dilakukan setiap hari senin pagi sampai siang atau dengan waktu selama 5 jam.Dalam sebulan ada terdapat 4 minggu dan 5 minggu sehingga waktu planning downtime berbeda-beda.

Kegiatan tersebut adalah dengan melakukan pengecekkan atau monitoring pada oil daring, ngegris, bering press, conveyor serta elevator. Loading time adalah waktu bersih yang tersedia dalam menjalankan proses produksi, jadi nilai loading time didapat dari hasil pengurangan jumlah jam kerja dengan planned downtime. Setelah didapatkan nilai loading time untuk setiap bulannya, kemudian dilakukan perhitungan operating time yang digunakan untuk menghitung availability. Operating time adalah waktu yang digunakan untuk menjalankan proses produksi tanpa memperhitungkan downtime. Downtime merupakan waktu dimana mesin berhenti produksi dikarenakan keadaan yang tidak terduga.

Pada stasiun KCP biasanya produksi berhenti apabila terdapat 2 faktor yaitu dari faktor internal maupun eksternal. Faktor internal yang menyebabkan terhentinya proses produksi yaitu terjadinya kerusakan dan perbaikan pada mesin press dan faktor eksternal yaitu adanya perbaikan distasiun Biogas (sebagai penyuplai sumber tenaga) untuk menjalankan proses produksi seperti perbaikan ciller, gas engine off (bocor valve air pendingin) ataupun adanya kendala pada stasiun $\mathrm{KCP}$ yang dapat mengganggu jalannya proses produksi seperti perbaikan mesin press trip. Operating time pada PT.X disajikan pada Tabel 2.

Tabel 2. Perhitungan Operating Time

\begin{tabular}{clccc}
\hline No & Bulan & Loading Time (menit) & Downtime (menit) & Operating Time (menit) \\
\hline 1 & Agustus & 43.440 & 777 & 42.663 \\
2 & September & 33.000 & 1410 & 31.590 \\
3 & Oktober & 43.140 & 1371 & 41.769 \\
4 & November & 33.000 & 318 & 32.682 \\
5 & Desember & 43.140 & 180 & 42.960 \\
\hline
\end{tabular}

Pada Tabel 2 diketahui bahwa pada bulan Agustus operating time pada stasiun KCP adalah 42.663 menit. Waktu tersebut didapat dari hasil pengurangan loadingtime 43.440 menit dengan waktu downtime selama 777 menit. Pada bulan September operating time hanya selama 31.590 dikarenakan waktu downtime yang tinggi yaitu selama 1.410 menit dengan waktu loading 33.000 menit. Pada bulan Oktober memiliki waktu loading selama 43.140 menit dengan downtime selama 1.371 menit, dapat diketahui operating timeyaitu selama 41.769 menit. Pada bulan November memiliki loading time 33.000 menit dengan downtime yang cukup rendah yaitu 318 menit dan didapat operating time yaitu selama 32.682 menit. Pada bulan Desember memilikioperating time yang paling lama yaitu 42.960 dengan downtime yang paling kecil yaitu hanya 180 menit dengan loading time 43.140 menit. Pada bulan Agustus sampai bulan Desember dapat diketahui bahwa memiliki waktu operating time yang berbeda-beda karena dipengaruhi jumlah hari yang berbeda setiap bulannya serta downtime yang terjadi tidak dapat diprediksi jenis kerusakan atau perbaikan.

Dari hasil perhitungan loading time yang telah didapat, kemudian dapat dilakukan perhitungan availability. Availability merupakan ratio yang menggambarkan pemanfaatan waktu yang tersedia untuk kegiatan proses produksi. Untuk mencari nilai availability memerlukan hasil data loading time, downtime dan operating time. Hasil perhitungan Availability disajikan pada Tabel 3.

Tabel 3. Hasil Perhitungan Availability

\begin{tabular}{llcccc}
\hline No & Bulan & $\begin{array}{c}\text { Loading Time } \\
\text { (menit) }\end{array}$ & $\begin{array}{c}\text { Downtime } \\
\text { (menit) }\end{array}$ & $\begin{array}{c}\text { Operating Time } \\
\text { (menit) }\end{array}$ & Availability(\%) \\
\hline 1 & Agustus & 43.440 & 777 & 42.663 & 98,21 \\
2 & September & 33.000 & 1410 & 31.590 & 92,74 \\
3 & Oktober & 43.140 & 1371 & 41.769 & 96,82 \\
4 & November & 33.000 & 318 & 32.682 & 99,04 \\
5 & Desember & 43.140 & 180 & 42.960 & 99,58 \\
\hline
\end{tabular}


Berdasarkan hasil perhitungan yang disajikan pada Tabel 3 dapat diketahui bahwa persentase availability pada bulan Agustus yaitu sebesar 98,21\%, bulan September memiliki nilai terendah yaitu hanya sebesar $92,74 \%$ dikarenakan jumlah jam kerja pada bulan tersebut hanya 30 hari, planning downtime dilakukan sebanyak 4 kali atau 4 minggu dan memiliki waktu downtime tertinggi yaitu selama 1410 menit, nilai availability mengalami kenaikan yaitu menjadi sebesar $96,82 \%$ pada bulan Oktober, 99,04\% pada bulan November dan bulan Desember merupakan nilai availability tertinggi dari bulan sebelumnya yaitu sebesar $99,58 \%$ hal ini dikarenakan waktu downtime yang relatif kecil yaitu hanya 180 menit selama sebulan.

\section{Performance Rate}

Performance Ratemerupakan suatu rasio yang menggambarkan kemampuan dari mesin/peralatan dalam menghasilkan suatu produk. Data yang diperlukan untuk mencari nilai performance rate yaitu data jumlah produksi, waktu siklus, dan operating time. Perhitungan performance rate dari bulan Agustus hingga bulan Desember disajiakan dalam Tabel 4.

Tabel 4. Perhitungan Performance Rate

\begin{tabular}{llcccc}
\hline No & \multicolumn{1}{c}{ Bulan } & $\begin{array}{c}\text { Jumlah produksi } \\
(\mathrm{kg})\end{array}$ & $\begin{array}{c}\text { Waktu siklus } \\
(\text { menit })\end{array}$ & $\begin{array}{c}\text { Operating time } \\
(\mathrm{menit})\end{array}$ & $\begin{array}{c}\text { Performance } \\
\text { Rate }(\%)\end{array}$ \\
\hline 1 & Agustus & 286.221 & 0,08 & 42.663 & 53,67 \\
2 & September & 273.539 & 0,08 & 31.590 & 69,27 \\
3 & Oktober & 434.209 & 0,08 & 41.769 & 83,16 \\
4 & November & 391.254 & 0,08 & 32.682 & 95,77 \\
5 & Desember & 478.645 & 0,08 & 42.960 & 89.13 \\
\hline
\end{tabular}

Pada Tabel 4 dapat dilihat hasil perhitungan performance rate mesin first press selama 5 bulan terakhir tahun 2018 yaitu Agustus, September, Oktober, November dan Desember. Dapat diketahui bahwa waktu siklus untuk produksi selama 0,08 didapat dari perhitungan pada SOP perusahaan tentang kapasitas produksi mesinfirstpress yaitu $750 \mathrm{~kg} / \mathrm{jam}$.

Data informasi jumlah produksi kernel, yang mana jumlah produksi yang disajikan pada tabel tersebut merupakan data yang diasumsikan dari hasil proses produksi pada stasiun Kernel Crushing Plant (KCP) selama 5 bulan. Pada bulan Agustus diketahui jumlah kernel yang diproduksi sebanyak $286.221 \mathrm{~kg}$ dengan operating time selama 42.663 menit dengan nilai performance rate mesin sebesar $53,67 \%$ yang merupakan nilai performance terendah dikarenakan waktu operating yang cukup tinggi namun hasil produksi selama sebulan tidak sesuai antara operating time dengan jumlah produksi yang relatif jauh berbeda.

Pada bulan September mengalami kenaikan persentase performance rate yaitu sebesar $69,27 \%$ dengan jumlah produksi sebanyak $273.539 \mathrm{~kg}$ dan memiliki operating time 31.590 menit. Pada bulan Oktober jumlah produksinya sebesar $434.209 \mathrm{~kg}$ dengan operating time selama 41.769 menit dan didapat nilai performance rate yaitu sebesar $83,16 \%$. Pada bulan November memiliki nilai performance rate tertinggi yaitu sebesar 95,77\% dengan jumlah produksi sebanyak $391.254 \mathrm{~kg}$ dengan waktu operating 32.682 menit dikarenakan operating time yang cukup rendah tetapi jumlah produksi di bulan tersebut cukup banyak sehingga dapat diketahui bahwa kinerja mesin dapat berjalan secara optimal dengan waktu downtime yang kecil yaitu hanya 318 menitdan bulan Desember jumlah produksi selama sebulan yaitu sebanyak $478.645 \mathrm{~kg}$ dengan waktu operating time 42.960 menit dan persentase performance rate sebesar $89,13 \%$.

Hasil performance rate memiliki nilai yang berbeda-beda setiap bulannya, ada beberapa penyebab yang mengakibatkan tinggi rendahnya nilai performance rate yaitu pertama mesin karena mesin yang digunakan untuk proses produksi merupakan mesin lama sehingga kinerja mesin sudah tidak optimal lagi seperti sering mengalami kerusakan dan perbaikan, karena hal tersebut mengakibatkan proses produksi tidak berjalan dengan lancar dan jumlah produksi menjadi berkurang. Kedua yaitu bahan baku produksi (kernel) yang diproduksi memiliki kualitas yang kurang bagus seperti banyaknya cangkang, masih adanya nut, serta kernel dari TBS yang masih mentah kebanyakan kernel tersebut berasal dari PKS lain. 


\section{Quality Rate}

Data yang digunakan untuk mendapatkan nilai quality rate diantaranya adalah data jumlah produksi perbulan, dirty (kotoran),dan reject (jumlah kotoran). Pada data jumlah produksi data yang diasumsikan dari hasil produksi kernel pada stasiun Kernel Crushing Plant (KCP) selama 5 bulan. Tinggi rendahnya persentase quality rate dipengaruhi oleh jumlah kotoran yang terdapat pada bahan baku (kernel) yang produksi. Semakin tinggi jumlah kotoran pada kernel maka akan semakin kecil quality rate mesin first press, sebaliknya jika semakin kecil jumlah kotorannya maka akan semakin tinggi quality rate mesin first press. Hasil perhitungan quality rate dapat dilihat pada Tabel 5.

Tabel 5. Perhitungan Quality Rate

\begin{tabular}{llcccc}
\hline No & Bulan & Jumlah Produksi $(\mathrm{kg})$ & Dirty $(\%)$ & Reject $(\mathrm{kg})$ & Quality rate (\%) \\
\hline 1 & Agustus & 286.221 & 10,76 & 30.797 & 89,24 \\
2 & September & 273.539 & 10,58 & 28.940 & 89,42 \\
3 & Oktober & 434.209 & 11,39 & 49.456 & 88,61 \\
4 & November & 391.254 & 9,89 & 38.695 & 90,11 \\
5 & Desember & 478.645 & 9,83 & 47.051 & 90,17 \\
\hline
\end{tabular}

Pada bulan Agustus diketahui jumlah produksi kernel sebanyak $286.221 \mathrm{~kg}$ dengan persentase dirty sebesar $10,76 \%$ dari jumlah produksi yaitu sebanyak $30.797 \mathrm{~kg}$ dihitung dengan menggunakan rumus dapat diketahui persentase quality rate produksi yaitu sebesar $89,24 \%$. Pada bulan September jumlah kernel yang diproduksi sebanyak $273.539 \mathrm{~kg}$ dengan persentase kotoran sebesar $10,58 \%$ dari jumlah produksi yaitu $28.940 \mathrm{~kg}$ dan didapat hasil quality rate sebesar $89,42 \%$. Pada bulan Oktober mengalami penurunan quality rate menjadi $88,61 \%$ dengan jumlah produksi yang cukup banyak yaitu $434.209 \mathrm{~kg}$, namun jumlah kotoran pada kernel yang tinggi yaitu 11,39\% atau $49.456 \mathrm{~kg}$ sehingga hal tersebut menyebabkan menurunnya persentase quality rate. Pada bulan November jumlah produksi sebanyak $391.254 \mathrm{~kg}$ dengan persentase kotoran sebesar 9,89\% dari jumlah produksi yaitu sebanyak $38.695 \mathrm{~kg}$ dapat diketahui quality rate pada bulan November sebesar 90,11\%. Pada bulan Desember memiliki quality rate terbaik dari bulan lainnya yaitu sebesar 90,17\% dengan persentase kotoran yang rendah yaitu $9,83 \%$ atau $47.051 \mathrm{~kg}$ dari jumlah produksi yang olah sebanyak $478.645 \mathrm{~kg}$ hal tersebut yang membuat tingginya persentase quality rate pada mesin first press.

\section{Overall Equipment Effectiveness(OEE)}

Overall Equipment Effectiveness(OEE) adalah pengukuran dalam Total Productive Maintenance (TPM) yang digunakan untuk menghitung keefektifan sebuah mesin atau peralatan secara aktual.Nilai OEE mesin first press(Tabel 6) dilakukan dengan mengumpulkan hasil perhitungan dari masing-masing faktor yaitu persentase availability, performance rate, quality rate sehingga dapat mencari nilai OEE dengan cara mengalikan ketiga faktor tersebut.

Tabel 6. Perhitungan Overall Equipment Effectiveness

\begin{tabular}{llcccc}
\hline No & Bulan & Availability (\%) & Performance Rate (\%) & Quality Rate (\%) & Nilai OEE (\%) \\
\hline 1 & Agustus & 98,21 & 53,67 & 89,24 & 47,04 \\
2 & September & 92,74 & 69,27 & 89,42 & 57,44 \\
3 & Oktober & 96,82 & 83,16 & 88,61 & 71,34 \\
4 & November & 99,04 & 95,77 & 90,11 & 85,47 \\
5 & Desember & 99,58 & 89,13 & 90,17 & 80,03 \\
& Rata-rata & 97,28 & 78,20 & 89,51 & 68,26 \\
\hline
\end{tabular}

Nilai OEE pada bulan Agustus sampai Desember berbeda-beda, pada bulan Agustus memiliki nilai persentase sebesar 47,04\%, bulan September sebesar 57,44\%, bulan Oktober $71,34 \%$, bulan November sebesar 85,47\%, dan bulan Desember sebesar 80,03\%. Hal tersebut dipengaruhi karena rendahnya nilai pada performance rateartinya mesin first press memiliki kemampuan yang kurang baik karena memiliki jam kerja yang lama namun hasil produksi masih kurang produktif disebabkan oleh kualitas kernel yang diproduksi dan kinerja mesin yang sudah tidak optimal lagi.Untuk membandingkan nilai OEE mesin first press dengan Nilai OEE Standar Internasional yaitu dengan 
cara dicari rata-rata nilai pada setiap faktor.Perbandingan nilai OEE Standar Internasional dengan Nilai OEE mesin first pressdi stasiun KCP yang disajikan pada Tabel 7.

Tabel 7. Perbandingan Nilai OEE

\begin{tabular}{lcc}
\hline \multicolumn{1}{c}{ OEE Factor } & Nilai OEE Standar Internasional (\%) & Nilai OEE Mesin First Press (\%) \\
\hline Availability & 99 & 97,28 \\
Performance Rate & 95 & 78,20 \\
Quality Rate & 99 & 89,51 \\
OEE & 85 & 68,26 \\
\hline
\end{tabular}

Nilai Standar Internasioal Availability sebesar 99\% namun nilai Availabilty pada mesin first press masih dibawah standar yang telah ditetapkan yaitu sebesar 97,28\%. Pada performance rate mesin masih dibawah standar yaitu hanya sebesar 78,20\% dengan standar Internasional sebesar 95\%. Pada quality rate standar yang ditetapkan adalah 99\% sedangkan nilai OEE mesin first press hanya sebesar 89,51\%. Jadi nilai OEE pada mesin first press di PT. X masih dibawah standar yaitu 68,26\% dengan Nilai OEE Standar Internasional sebesar 85\%.Masih rendahnya nilai OEE mesin first press di stasiun KCP PT. X disebabkan oleh beberapa faktor, yaitu umur mesin yang sudah tua sehingga sering mengalami kerusakan, proses maintenance yang memakan waktu lama, dan kualitas kernel diolah yang rendah.

\section{KESIMPULAN}

Berdasarkan penelitian yang telah dilakukan, maka didapatkan kesimpulan bahwa nilai OEE pada mesin first press di stasiun KCP PT. X belum memenuhi standar internasional yang telah ditetapkan. Pada nilai OEE first press diketahui memiliki nilai availability sebesar 97,28\% sedangkan standar Internasionalnya sebesar 99\%. Pada nilai performance rate sebesar 78,20\% nilai tersebut dibawah nilai standar internasional yaitu sebesar 95\%. Pada nilai quality mesin first press hanya sebesar $89,51 \%$ untuk nilai standarnya sebesar $95 \%$ sedangkan nilai OEE untuk mesin first press pada stasiun KCP memiliki nilai sebesar $68,26 \%$ dengan selisih yang cukup jauh dengan nilai standar Internasional yaitu sebesar 85\%. Penyebab rendahnya nilai OEE mesin first press di stasiun KCP PT. $\mathrm{X}$ karena faktor umur mesin yang sudah tua, proses maintenance yang lama, serta kualitas kernel yang rendah.

\section{DAFTAR PUSTAKA}

Alvira, D., Helianty, Y., dan Prassetiyo, H. 2015. Usulan Peningkatan Overall Equipment Effectiveness (OEE) pada MesinTapping Manual dengan Meminimumkan Six Big Losses. Reka Integra. Volume (3) : 240-251. Nomor 03.

Arifianto, A. 2018. Penerapan Total Productive Maintenance (TPM) Dengan Menggunakan Metode Overall Equipment Effectiveness (Studi Kasus: PT. Triangle Motorindo). Fakultas Teknologi Industri, Universitas Islam Indonesia. Yogyakarta.

Asgara, B.Y., dan Hardono, G. 2014. Analisis Efektivitas Mesin Overhead Crane Dengan Metode Overall Equipment Effectiveness (OEE) di PT. BTU, Divisi Boarding Bridge. INASEA. Volume (15) : 62-70. Nomor 1

Hartman. E. 1992. Successfully Installing TPM in a NonJapanese Plant. Pittsburgh, PA, TPM Press, Inc.,

Mohamad. 2015. Penerapan Overall Equipment Effectiveness (OEE) Dalam Implementasi Total Productive Maintenance (TPM) Studi Kasus Di PT. Adi Satria Abadi Kalasan. Fakultas Teknologi Industri. Universitas Pembangunan Nasional "Veteran". Yogyakarta.

Pangaribuan, L. C. 2018. Laporan Kerja Praktek Di PT. Perkebunan Nusantara VI Unit PKS Bunut. Fakultas teknologi Industri, Universitas Atma Jaya. Yogyakarta.

Rahmad, Pratikto., dan Wahyudi, S. 2012. Penerapan Overall EquipmentEffectiveness (OEE) Dalam Implementasi Total Productive Maintenance (TPM) (Studi Kasus di Pabrik Gula PT. Y). Jurnal Rekayasa Mesin. Volume (3) : 431-437. Nomor 3. 
Rahmadani, S. D. 2015. Penganalisaan Standard Industri CPO Dan Kernel Di PT. Sinar Sawit Lestari Damuli. Laporan Praktek Kerja Lapangan. Universitas Negeri Medan.

Rajput, H.S., dan Jayaswal, P. 2012. A Total Productive Maintenance (TPM) Approach To Improve Overall Equipment Efficiency. International Journal of Modern Engineering Research (IJMER). Volume (2) : 4383-4386. Nomor 6.

Suhardi, J. 2013. Alat Dan Mesin Pengolahan Kelapa Sawit Menjadi CPO (Crude Palm Oil). Politeknik Pertanian Universitas Andalas. Payakumbuh.

Supriyadi., Ramayanti, G., Afriansyah, R. 2017. Analisis Total Productive Maintenance Dengan Metode Overall Equipment Effectiveness dan Fuzzy Failure Mode and Effect Analysis. Sinergi. Volume (21) : 165-172. Nomor 3. DOI : doi.org/10.22441/sinergi.2017.3.002

Thomas R. Pomorski. 2004. Total Productive Maintenance (TPM) Concepts and Literature Review, (Brooks Automation, Inc.) 